\title{
Protocolo de Observaçáo do Desempenho de Crianças com Deficiência Física: Construção, Aplicação e Análise de Dados ${ }^{1}$ Observation Protocol of Physically Disabled Children's Performance: Construction, Aptlication and Data AnaLYSIS
}

\author{
Mariana Dutra ZAFANI ${ }^{2}$ \\ Sadao OMOTE ${ }^{3}$ \\ Luciana Ramos BALEOTTI ${ }^{4}$
}

\begin{abstract}
RESUMO: o artigo descreve os procedimentos para a construção, aplicação e análise de dados de um instrumento de avaliação denominado Protocolo de Observação do Desempenho de Crianças com Deficiência Física na Realização de Atividades de Pintura e Colagem. Este protocolo visa a identificar a percepçáo dos pais e a dos professores acerca de dois aspectos do desempenho de crianças com deficiência física, a saber, capacidade ou incapacidade e independência ou dependência com que é executada uma atividade habitualmente realizada no contexto escolar. Participaram do estudo 11 professoras, sendo três da Educação Infantil e oito do Ensino Fundamental, e três juízes com experiência em Educação Especial. Foram utilizados dois questionários, um visava a avaliar, segundo a percepção das professoras, a adequação das atividades de pintura e colagem elaboradas para as crianças de quatro a nove anos de idade, e o outro, verificar a opiniấo dos juízes quanto à adequaçáo do instrumento proposto, para o fim a que se destina. Uma série de procedimentos foi realizada até alcançar a versão final do instrumento. Finalizada a sua construção, foram sistematizados os procedimentos para a sua aplicação e análise de dados. As aplicaçôes iniciais do instrumento têm revelado que este está cumprindo com o seu objetivo principal, que é o de mensurar a percepção que pais e professores têm do desempenho de crianças com deficiência física em uma atividade habitualmente realizada no contexto escolar. Os resultados sugerem também a sua adequaçáo quanto à linguagem e formato para a populaçáo que faz o seu uso.
\end{abstract}

PALAVRAS-CHAVE: Educação Especial. Instrumentos de Mensuração. Percepção Social. Pais. Professores.

\begin{abstract}
The article describes the procedures of construction, application and data analysis of an instrument of evaluation labeled Observation Protocol of Physically Disabled Children's Performance in the Accomplishment of Painting and Pasting Activities. This protocol seeks to identify parent and teacherperception concerning two aspects of physically disabled children's performance, i.e., the capacity or inability and independence or dependence with which they accomplish an activity they are familiar with in the school setting. Elevenpreschool and elementary school teachers and three researchers with experience in the area of Special Education participated in the study. A questionnaire was used to evaluate, according to the teachers' perception, the suitability of the painting and pasting activities proposed to four to nine year old children. Another questionnaire was used to examine the opinion of the researchers about the adequacy of the proposed instrument for the intended aim. A series of procedures was accomplished to reach the final version of the instrument. Once finalized, the procedures for its application and data analysiswere systematized. The initial applications of the instrument have suggested that the instrument is fulfilling its main purpose, that is, the measurement of parents' and teachers' perception of physically disabled children's performance in agiven activity that is often performed in the classroom. The results also suggest it be adapted regarding language and format for the population that will be using it.
\end{abstract}

KEYWORDS: Special Education. Measurement Instruments.Social Perception. Parents. Teachers.

\footnotetext{
${ }^{1} \mathrm{O}$ artigo relata parte do estudo apresentado na Dissertação de Mestrado defendida pela primeira autora, disponível na biblioteca da Faculdade de Filosofia e Ciências, Unesp, campus de Marília. Apoio financeiro: Capes.

${ }^{2}$ Terapeuta Ocupacional, Doutoranda em Educação, Faculdade de Filosofia e Ciências, UNESP, Marília, SP, Brasil. marianadz@ig.com.br

${ }^{3}$ Livre-docente em Educação Especial, Professor Titular do Departamento de Educação Especial e Professor Orientador do Programa de Pós-Graduação em Educação, Faculdade de Filosofia e Ciências, UNESP, Marília, SP, Brasil. somote@uol.com.br

${ }^{4}$ Terapeuta Ocupacional, Doutora em Educação, Docente do Curso de Terapia Ocupacional do Departamento de Fisioterapia e Terapia Ocupacional, Faculdade de Filosofia e Ciências, UNESP, Marília, SP, Brasil. baleotti@marilia.unesp.br
} 


\section{INTRODUÇÁo}

No contexto da educação inclusiva, refletir sobre a reação da audiência frente à deficiência é de especial interesse, considerando que, além da eliminação de barreiras ambientais, a eliminação de barreiras atitudinais é de igual importância, pois ambas dificultam ou impedem a participação efetiva do aluno com deficiência no cotidiano escolar.

Segundo Omote et al. (2005), um dos fatores mais decisivos para a construção da educação inclusiva é o meio social representado por diferentes segmentos. Com relação às crianças com deficiência em idade escolar, os pais e os professores representam, em primeira instância, as pessoas que estão diretamente envolvidas com elas e são segmentos fundamentais para a promoçăo do ensino inclusivo e para o desenvolvimento delas.

Tendo em vista a importância da família e da escola para o desenvolvimento da criança, Ferreira e Barrera (2010) apontam a necessidade de haver uma maior integraçáo entre esses dois segmentos. Apesar dos benefícios que essa parceria traz ao aluno, a sua efetivação não é ainda uma realidade encontrada na maioria das escolas brasileiras. Segundo Silva e Mendes (2008, p. 233) "[...] tanto familiares quanto profissionais ainda precisam amadurecer no sentido de saber qual é o seu papel na parceria e qual é o papel do outro".

Para que o processo de desenvolvimento infantil seja mediado de maneira positiva, os parâmetros dos contextos significativos de uma criança com comprometimentos, entre eles a escola e a família, necessitam interagir em harmonia entre si e com as características pessoais da criança (OLIVEIRA, 2012). No entanto, as variáveis pessoais como valores, crenças, expectativas, preconceito, e o vínculo e envolvimento diferenciados que pais e professores mantêm com a criança, atrelados à falta de diálogo entre a família e a escola, influenciam as percepçóes e expectativas que têm em relaçáo às possibilidades, dificuldades e necessidades da criança com deficiência. Cada um deles pode nutrir expectativas distintas em relação à criança e prover auxílios ou cobranças diferenciadas.

Nesse sentido, é importante que se investiguem tanto a natureza da percepção diferenciada de professores e pais quanto as variáveis envolvidas que podem determinar diferentes modos de percepçáo da parte de pessoas que mantêm vínculos de natureza diferente com a criança alvo da percepção.

A literatura especializada sobre a percepção social aponta que tanto as características do alvo quanto as do sujeito da percepçáo interferem na formaçáo do percepto (HASTORF; SCHNEIDER; POLEFKA, 1973; RODRIGUES; ASSMAR; JABLONSKI, 2005). As duas partes estão envolvidas no processo perceptivo, o qual não pode ser tratado como uma apreensão rigorosa, ou essencialmente enviesada, do objeto de percepção.

Assim, mais do que considerar como viés ou distorçôes perceptivas, é preciso buscar o significado da percepção levando em conta a natureza da relação entre o percebedor e o percebido. Isto é necessário quando essa relaçáo é eivada de emoçóes e/ou determinada por compromissos sociais.

Estudos da natureza da percepçáo de uma mesma criança, na perspectiva dos familiares e na dos professores, podem contribuir para a compreensão do envolvimento desses atores no processo inclusivo dessa criança em contextos escolares. Tal compreensão pode ser um 
importante ponto de partida na jornada em busca de procedimentos que auxiliem as escolas e famílias a desenvolverem um trabalho colaborativo para prover educação integral e de qualidade a todas as crianças, em especial àquelas com deficiências.

Com o intuito de contribuir para identificar algumas variáveis pessoais dos atores envolvidos, que precisam ser consideradas no equacionamento das condiçóes necessárias para a construção da Educação Inclusiva, procurou-se investigar a natureza da percepção diferenciada de uma mesma criança por parte de seus pais e de professores. Investigaçóes sólidas requerem instrumentos capazes de coletar dados confiáveis e adequados ao objeto de estudo. Assim, inicialmente foi construído um instrumento de coleta de dados, cujas caracterísiticas e procedimentos de uso apresentam peculiaridades metodológicas que recomendam descrevê-lo detalhadamente. Todo o processo de construção e os procedimentos de uso levantam importantes questóes metodológicas, o que justifica a publicação de um relato técnico como este.

O objetivo deste relato é o de descrever os procedimentos para a construção, aplicação e análise de dados do instrumento de avaliação denominado Protocolo de Observação do Desempenho de Crianças com Deficiência Física na Realização de Atividades de Pintura e Colagem 5 , o qual visa identificar a percepção dos pais e a dos professores acerca de dois aspectos do desempenho de crianças com deficiência física em uma atividade habitualmente realizada no contexto escolar. Esses aspectos referem-se à capacidade ou incapacidade e independência ou dependência com que as crianças realizam as atividades propostas. $\mathrm{O}$ instrumento se destina à avaliação da percepção do desempenho de crianças na faixa etária de quatro a nove anos.

\section{Método}

O presente estudo foi aprovado pelo Comitê de Ética em Pesquisa da Faculdade de Filosofia e Ciências da Universidade Estadual Paulista - FFC/UNESP/Marília - SP sob o protocolo de número 0125/2011.

\subsection{Participantes}

Participaram 11 professoras, sendo uma da Educação Infantil I, duas da Educação Infantil II e oito do $1^{\circ}$ ao $4^{\circ}$ ano do Ensino Fundamental, as quais eram duas de cada ano. Além destas, participaram como juízes três pesquisadores com experiência na área de Educação Especial, sendo duas pedagogas e uma terapeuta ocupacional.

\subsection{Material}

Foi utilizado um questionário composto por três perguntas para avaliar, segundo a percepção das professoras da Educação Infantil e do Ensino Fundamental, a adequação das atividades de pintura e colagem elaboradas para as crianças de quatro a nove anos de idade.

\footnotetext{
${ }_{5}^{5}$ Outros artigos em preparação tratarão do estudo das percepçốes do desempenho de crianças com deficiência física, por parte de seus pais e professores, realizado com o uso do instrumento aqui descrito. O instrumento será doravante referido por Protocolo de Observação.
} 
Utilizou-se também um questionário adicional composto por cinco perguntas, com o objetivo de verificar a opinião dos juízes quanto à adequação do instrumento proposto, para o fim a que se destina.

\subsection{Procedimentos de ConstruÇáo do instrumento}

Decidiu-se pela construção do instrumento em decorrência do fato de não ter sido encontrado na literatura instrumentos que tivessem as propriedades consideradas necessárias para atender a demanda do estudo: o instrumento deveria permitir a investigaçáo da percepção que os pais e professores têm acerca do desempenho de crianças com deficiência física em uma atividade habitualmente realizada no contexto escolar, no aspecto relativo à capacidade ou incapacidade na sua execução e a independência ou dependência com que a realiza. Tal instrumento deve possuir uma linguagem acessível e de fácil compreensão tanto para os pais quanto para os professores; e deve permitir aos pais e professores avaliarem de maneira autônoma o desempenho da criança.

$\mathrm{Na}$ literatura especializada da área, foram encontrados apenas instrumentos que serviram como referência para a construção do instrumento ora apresentado. Foram localizados a Avaliação de Habilidades Motoras e de Processo - Versão Escolar (School-AMPS) traduzida e adaptada para crianças brasileiras de quatro a oito anos de idade por Faria (2004), a School Function Assessment (SFA) desenvolvida por Coster e colaboradores em 1998 (COSTER et al., 1998), o Pediatric Evaluation of Disability Inventory (PEDI) desenvolvido por Haley e colaboradores (1992) e traduzido e adaptado para o uso no Brasil por Mancini (2005), o Questionário de Avaliação da Saúde traduzido e adaptado para a população brasileira por Ferraz e colaboradores em 1990 (FERRAZ et al., 1990) e a Medida de Independência Funcional (MIF), que faz parte de um Sistema de Dados Uniformizados para Reabilitação Médica (UDSMR, 1993).

Para a construção de um instrumento de mensuração confiável, é necessário adotar alguns cuidados básicos, destacando-se a conceituação clara do objeto de mensuração, a adoção de procedimentos para uniformização das condiçóes de mensuração (padronização das instruçôes, da disposição do ambiente e da apresentação dos materiais), o uso de juízes como parte do processo de avaliação da adequação de materiais e/ou procedimentos, o desenvolvimento de critérios para a interpretação dos resultados obtidos e o estudo piloto para a verificação empírica inicial da adequação do instrumento. Tais cuidados são necessários para que se possam gerar boas medidas do objeto que se pretende mensurar. Além disso, o instrumento deve apresentar validade social e estar adequado à população que fará o seu uso.

A princípio, não houve pretensão de validar e padronizar o instrumento elaborado, uma vez que o estudo do fenômeno investigado é ainda incipiente, sendo muito pouco conhecida a sua natureza. Nessas condiçóes, poderia náo se justificar todo o investimento na validação e padronização do instrumento, até porque, como se verá a seguir, a confecção do material a ser usado para cada caso e a avaliação de percepção de pais e professores são trabalhosas demandando muito tempo. Entretanto, algumas medidas foram adotadas para garantir confiabilidade dos dados coletados por meio desse instrumento.

Para mensurar e comparar a percepção dos pais e a dos professores, é necessário que observem uma mesma situação padronizada de desempenho da criança com deficiência física. 
Em virtude disso, convencionou-se que os pais e professores iriam assistir a uma filmagem da criança desempenhando uma atividade habitualmente realizada no contexto escolar e, a partir da observação desta filmagem, iriam preencher o instrumento, com base em suas percepçóes acerca da capacidade ou incapacidade e independência ou dependência da criança.

Uma vez que o interesse do estudo recai sobre a percepção daqueles que mantêm vínculos de natureza distinta com a criança alvo da percepção, os pais e professores devem assistir a filmagem de seus próprios filhos ou alunos. Portanto, cada aluno deve ser filmado realizando a atividade que é proposta a crianças da faixa etária à qual pertence. A filmagem de cada criança deve ser assistida pelo respectivo pai e professor.

$\mathrm{O}$ instrumento deve avaliar a percepção que pais e professores têm de crianças com idade entre 4 a 9 anos, inseridas no ensino especial ou no ensino regular. A criança deve possuir déficit motor em um ou ambos os membros superiores, podendo este estar acompanhado de outros déficits motores em outros segmentos do corpo e não deve apresentar visão subnormal, cegueira, surdez ou deficiência intelectual grave. Deve ter nível de compreensão satisfatório para entender o que lhe é solicitado na execução da atividade quando da sua filmagem.

Após estas opçóes determinadas, a etapa seguinte para a construção do instrumento consistiu em elaborar as atividades do contexto escolar em relação à qual os pais e os professores iriam observar e avaliar o desempenho das crianças com deficiência física.

A elaboração das atividades foi pautada em dois critérios: 1) as atividades deveriam estar inseridas na rotina escolar das crianças de quatro a nove anos de idade e 2) as atividades deveriam estar adequadas ao interesse e ao desenvolvimento neuropsicomotor das crianças daquela faixa etária.

Visando elaborar as atividades a serem executadas pelas crianças de quatro a nove anos de idade, foi realizada uma busca em livros de referência da área da Psicomotricidade, Pedagogia, Desenvolvimento Humano e Escolar procurando embasamento teórico necessário. Foram elaboradas três atividades de nível de complexidade diferenciado, presumidamente adequado para crianças de quatro a nove anos. Os resultados encontram-se descritos no item 3.1.

A fim de verificar a adequação das atividades elaboradas, estas foram apresentadas para 11 professoras participantes do estudo. A elas foram feitas três perguntas, com o propósito de: 1) identificar se as atividades elaboradas estavam adequadas em relação ao desenvolvimento neuropsicomotor e interesses das crianças daquela faixa etária; 2) identificar se a demanda das atividades apresentadas estava inserida na rotina escolar dos alunos daquela faixa etária, e 3) verificar se as professoras sugeriam alguma adequação para aquelas atividades apresentadas, pensando na faixa etária das crianças. A professora P1 do Infantil I e as professoras P2 e P3 do Infantil II analisaram a Atividade 1 (colagem de quatro peças para montar uma tartaruga e pintura dos desenhos), as professoras P4, P5, P6 e P7 examinaram a Atividade 2 (colagem de seis peças para montar um peixe e pintura dos desenhos) e as professoras P8, P9, P10 e P11, a Atividade 3 (colagem de oito peças para montar um leão e pintura dos desenhos). Os resultados estão descritos no item 3.2.

Finalizada a adequação das atividades, com base nas respostas das professoras ao questionário, a etapa seguinte consistiu em definir o formato do instrumento. Para atender ao 
propósito da pesquisa, o instrumento deve ser capaz de avaliar a percepção que pais e professores têm da habilidade motora ${ }^{6}$ e da habilidade de processo $^{7}$ da criança na execução da atividade. Assim, em cada item, que se refere a algum segmento do desempenho da criança, os pais e professores devem indicar a capacidade ou incapacidade e a indepedência ou dependência com que ela realiza a tarefa.

Para cumprir essas funções, o instrumento está dividido em duas seções. A Seção 1 contém itens que avaliam as habilidades motoras da criança na execução da atividade e a Seção 2 contém itens que avaliam as habilidades de processo da criança na execução da atividade. Em cada item do instrumento, há duas colunas, Coluna 1 e Coluna 2, contendo alternativas de respostas. A Coluna 1 tem quatro alternativas de respostas referentes a capacidade ou incapacidade da criança na execução da atividade e a Coluna 2 tem quatro alternativas de respostas referentes a independência ou dependência da criança na execução da atividade. No item 3.3 o formato do instrumento é apresentado de maneira detalhada.

Após a realização desse procedimento, iniciou-se a etapa de elaboração dos enunciados de cada item que compuseram a versão inicial do instrumento. $\mathrm{Na}$ redação dos enunciados, buscou-se utilizar linguagem simples e clara sem ambiguidades, viés ou ênfase em alguma direção.

Além dos cuidados acima, realizou-se a análise das atividades de pintura e colagem para identificar habilidades motoras e de processo envolvidas na execução dessas tarefas, com base em procedimento de análise de atividade comumente utilizado na prática terapêutico ocupacional $^{8}$. Na área da terapia ocupacional, a “[...] análise prévia da atividade tem como objetivo possibilitar seu conhecimento detalhado, permitindo a observação de suas propriedades específicas" (SILVA; EMMEL, 1993, p. 48). Na elaboração de alguns dos itens do instrumento, serviu de base a definição de alguns itens da versão brasileira da Avaliação de Habilidades Motoras e de Processo - Versão Escolar (School-AMPS) (FARIA, 2004). Os resultados referentes à elaboração dos itens encontram-se descritos em 3.3.

A fim de verificar a adequação da versão inicial do instrumento para o fim a que se destina, foi aplicado um questionário composto por cinco perguntas a três juízes com o intuito de obter a avaliação deles sobre os seguintes aspectos: a) se os itens do Protocolo de Observação possuem uma linguagem acessível e de fácil compreensão para os pais e professores; b) se as alternativas de respostas da Coluna 1 e Coluna 2 possuem uma linguagem acessível e são de fácil compreensão para os pais e professores; c) verificar se os itens do Protocolo de Observação estão nas seçóes corretas; d) verificar se o Protocolo de Observação é capaz de revelar a percepção dos pais e professores em relação ao desempenho da criança na atividade observada, e e) verificar se há alguma sugestão de alteração em algum item ou no Protocolo de Observação. Caso os juízes identificassem problemas nos aspectos investigados ou sugerissem modificaçóes no instrumento deveriam justificar o motivo para tal apontamento. Após este procedimento, as adequações e alteraçôes consideradas necessárias foram realizadas no instrumento, as quais estão descritas no item 3.4, resultando na versão final do instrumento.

\footnotetext{
${ }^{6}$ A habilidade motora pontua a eficiência da criança ao movimentar os objetos e a si própria no ambiente.

${ }^{7}$ A habilidade de processo pontua a qualidade do desempenho nas áreas de atenção, compreensão, noção espacial e percepção visual.

${ }^{8}$ Vale apontar que a primeira e a terceira autora são terapeutas ocupacionais e apresentam formação para realizar a análise de atividades.
} 


\section{Resultados E Discussótes}

O caminho percorrido até alcançar a versão final do instrumento foi constituído por etapas sequenciais em que o resultado de um procedimento determinava como deveria ser realizada a etapa seguinte. Entretanto, para enquadrar o relato no formato convencional, os procedimentos metodológicos foram preliminarmente descritos na sua íntegra e serão apresentados nos tópicos seguintes os resultados obtidos em cada etapa.

\subsection{ATIVIDADES ELABORADAS}

A padronização das atividades a serem observadas por pais e professores para avaliar o desempenho das crianças com deficiência física é uma exigência metodológica. Convém lembrar que a pesquisa, para cuja realização o instrumento ora descrito foi desenvolvido, tem como foco a percepção do desempenho de crianças com deficiência física pelos respectivos pais e professores. Assim, as atividades desenvolvidas pelas crianças foram escolhidas em função da sua adequação para o propósito de observação e avaliação em detalhe por parte dos pais e professores. Embora tenham sido escolhidas atividades relativamente corriqueiras do cotidiano escolar dessas crianças, não tem nehuma intenção de promover educação ou inclusão delas.

Com base nos critérios previamente estabelecidos e na literatura consultada (FERREIRA; CALDAS, 2002; SPODEK; SARACHO, 1998; GESELL, 1993, 2003), ficou definida a proposta de atividades de pintura e colagem, diferindo em nível de complexidade para as crianças de quatro a nove anos de idade.

Levando em conta a importância de as atividades estarem adequadas às competências motoras, cognitivas e perceptivas das crianças de diferentes idades, foram criadas três atividades diferentes de pintura e colagem (Atividade 1, Atividade 2, Atividade 3). As atividades apresentam graus de dificuldades diferenciados por meio do número de peças a serem coladas, habilidade necessária para diferenciá-las (percepção visual), complexidade dos desenhos a serem coloridos (destreza manual), habilidade necessária para discriminar figura-fundo em atividades que possuem sobreposição de peças (percepção visual) e complexidade da colagem, a qual exige domínio das relações espaciais.

A Atividade 1 é destinada às crianças de quatro e cinco anos de idade, consistindo na colagem de quatro peças para montar uma tartaruga e colorir os desenhos. A Atividade 2 é destinada às crianças de seis e sete anos de idade, sendo que elas devem colar seis peças para formar um peixe e colorir os desenhos. A Atividade 3 é destinada às crianças de oito e nove anos de idade e consiste da colagem de oito peças montando um leão e colorir os desenhos.

A faixa etária foi agrupada em três níveis (Nível 1: crianças de quatro e cinco anos, Nível 2: crianças de seis e sete anos, Nível 3: crianças de oito e nove anos), com a mesma atividade para as crianças de cada nível, considerando que poderia ser executada tanto pelas menores quanto pelas maiores, com diferença de apenas um ano, oferecendo maior desafio para as menores e um grau de dificuldade adequado e suficiente para as maiores.

Convencionou-se que para cada criança seriam entregues duas folhas: uma contendo os desenhos impressos já coloridos e a colagem de peças formando um animal, que serve de modelo para que a criança execute a atividade (Figura 1), e outra na qual a criança realiza a 
atividade (Figura 2) (papel sulfite com a impressão dos mesmos desenhos do modelo a ser pintado e um espaço em branco para colagem das peças, já recortadas, para formar um animal). Destaca-se que foram elaborados os moldes dos animais (tartaruga, peixe, leão) que seriam utilizados na colagem (peças recortadas em papel cartão colorido).

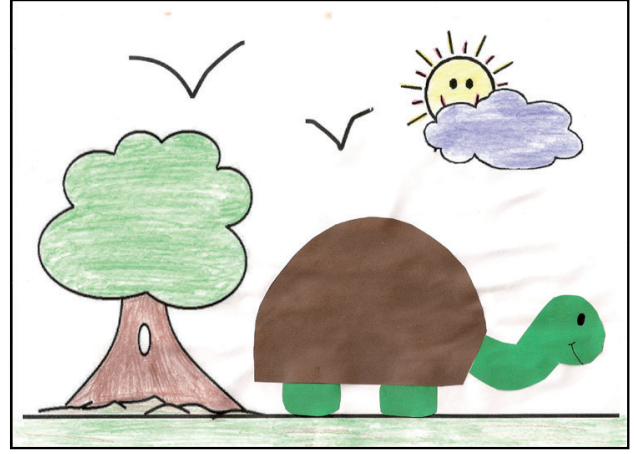

Figura 1- Atividade 1 = Modelo da atividade da tartaruga

Fonte: Zafani (2013, p. 42)

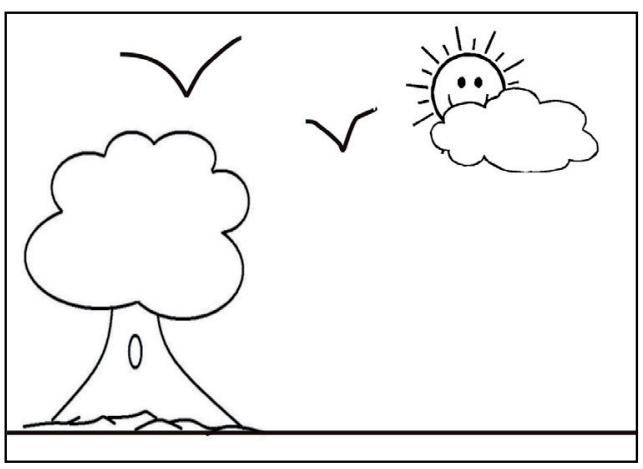

Figura 2- Atividade 1= Folha para a execução da atividade da tartaruga Fonte: Zafani (2013, p. 42)

\subsection{ANÁlISE DAS RESPOSTAS DAS PROFESSORAS PARA VERIFICAR A ADEQUAÇÃO DAS ATIVIDADES ELABORADAS}

A análise dos apontamentos feitos pelas professoras sobre a adequação das atividades elaboradas sugeriu a necessidade de aumentar o grau de dificuldade das Atividades 2 e 3 para as crianças de sete e nove anos, respectivamente. As professoras destas crianças consideraram que as atividades estavam aquém do desenvolvimento e interesse das crianças destas faixas etárias. A alteração no grau de dificuldade foi feita pelo aumento da complexidade da execução da tarefa de colagem. A Atividade 2 passou a ter sete peças ao invés de seis, e a Atividade 3 passou a ter nove peças ao invés de oito, o que exigiu das crianças de sete e nove anos maior domínio de habilidades de desempenho como atenção, percepção visual e noção espacial.

A maioria das professoras apontou também a necessidade de inserir as atividades de pintura e colagem num contexto significativo para as crianças. $\mathrm{O}$ apontamento foi acatado considerando que a contextualização das atividades pode torná-las mais atraentes e garantir maior envolvimento na sua execução. Diante disto, para cada uma das atividades de pintura e colagem foi elaborada uma história que deve ser contada antes de a criança iniciar a sua realização. As histórias elaboradas foram feitas no formato de livros ilustrados. Foram criadas três histórias 9 . A história da Tartaruguinha, que deve ser lida antes de propor a Atividade 1 para as crianças de quatro e cinco anos. A história do Peixe Molhado e o Fundo do Mar, que deve ser lida antes de propor a Atividade 2 para as crianças de seis e sete anos. A história do Circo do Senhor Leopoldo, que deve ser lida antes de propor a Atividade 3 para as crianças de oito e nove anos.

\footnotetext{
${ }^{9}$ As histórias elaboradas e os demais materiais citados neste artigo (Versão inicial e final do Protocolo de Observação, Descrição dos materiais e da organização da sala para a realização das atividades de pintura e colagem, Ficha de informaçóes sobre os materiais escolares e recursos das tecnologias assistivas utilizados pela criança para realizar a atividade de pintura e colagem, Roteiro de instruçóes que devem ser fornecidas as crianças de 4 a 9 anos, Roteiro de Análise de Atividade de Pintura e Colagem, Roteiro com exemplos de ajudas motoras e verbais que podem ser oferecidas para a criança durante a execução das atividades de pintura e colagem e Roteiro de instruçōes que devem ser passadas aos pais e professores em cada item) podem ser vistos na íntegra na dissertação de mestrado da primeira autora.
} 
Após as modificações nas atividades de pintura e colagem, foi sistematizado todo o procedimento de uso adequado das atividades para a consecução dos objetivos da pesquisa. Essa sistematização resultou em dois documentos: Descrição dos materiais e da organização da sala para a realização das atividades de pintura e colagem e a Ficha de informaçóes sobre os materiais escolares e recursos das tecnologias assistivas utilizados pela criança para realizar a atividade de pintura e colagem. Esta ficha coleta informaçóes junto aos pais e/ou professores sobre a locomoção, os materiais escolares e recursos das tecnologias assistivas utilizados pela criança em sala de aula, para verificar a necessidade de adequação/adaptação dos materiais que são oferecidos para a criança realizar a atividade, a fim de oferecer condiçóes semelhantes às que a criança vivencia na escola.

Foi elaborado também o Roteiro de instruçóes que devem ser fornecidas as crianças de quatro a nove anos, que contempla as informaçóes que devem ser dadas às crianças antes de iniciarem a atividade.

Após estas convenções, a etapa seguinte para a construção do instrumento consistiu em definir o formato do instrumento.

\subsection{DefiniÇÁo do FORMATO do INSTRUMENTO: SEÇÓES (SEÇÃo 1 E SEÇÃo 2), ALTERNATIVAS de respostas (Coluna 1 e Coluna 2) E ITENS}

O instrumento foi inspirado no formato da School-AMPS (FARIA, 2004), a qual é constituída por duas escalas: a de habilidades motoras e a de habilidades de processo. Considerou-se esse formato interessante, pois as duas escalas que compóem o instrumento fornecem uma análise global do desempenho da criança, ao contemplá-lo tanto do ponto de vista motor quanto de processo. Assim, convencionou-se que o instrumento seria constituído por duas seçôes. A Seção 1 seria constituída por itens que avaliam as habilidades motoras da criança na execução da atividade e a Seção 2 seria constituída por itens que avaliam as habilidades de processo da criança na execução da atividade.

Cada item é constituido por um enunciado, na forma de uma pergunta acerca de um episódio específico da sequência de ações realizadas na execução da atividade pela criança, acompanhado de alternativas de resposta. Os pais e professores devem avaliar dois aspectos de cada episódio - capacidade ou incapacidade na execução da ação e independência ou dependência com que a ação é executada pela criança. Assim, convencionou-se que em cada item haveria duas Colunas contendo as alternativas de respostas: Coluna 1 e Coluna 2. A Coluna 1 contém quatro alternativas de respostas referentes a capacidade ou incapacidade da criança na execução da atividade: capaz sem dificuldade, capaz com pouca dificuldade, capaz com muita dificuldade e incapaz. A Coluna 2 contém quatro alternativas de respostas referentes a independência ou dependência da criança na execução da atividade: náo precisa de ajuda, precisa de pouca ajuda, precisa de muita ajuda e a terapeuta executa este passo da tarefa sem a participação da criança ${ }^{10}$.

Os participantes teriam como tarefa assinalar uma alternativa de resposta de cada uma das Colunas em todos os itens do instrumento. Foi determinado que as alternativas de respostas seriam as mesmas para todos os itens do instrumento.

\footnotetext{
${ }^{10}$ No instrumento utiliza-se a palavra terapeuta, pois a pessoa responsável pela aplicação das atividades e do instrumento é assim reconhecida pelos pais e professores. No texto, utiliza-se avaliador porque não se refere ao status ocupacional da pessoa.
} 
Para a formulação das alternativas de respostas e do significado atribuído a cada uma delas, as quais devem permitir a avaliação da capacidade e incapacidade e independência e dependência do desempenho da criança em cada um dos itens do instrumento, constituíram-se como fontes de informação os critérios de pontuação de instrumentos que avaliam um ou os dois aspectos investigados, como School Function Assessment (SFA), Pediatric Evaluation of Disability Inventory (PEDI), Questionário de Avaliação da Saúde, School-AMPS e a Medida de Independência Funcional (MIF).

Por fim, para a elaboração dos itens, as atividades de pintura e colagem foram analisadas sob os parâmetros de análise de atividade voltada para a tarefa. Utilizou-se o Roteiro de Análise de Atividades proposto por Crepeau (2002), o qual passou por adaptaçóes para atender aos objetivos deste estudo. O Roteiro de Análise de Atividade de Pintura e Colagem contempla uma descrição breve das atividades, etapas sequenciais e descrição das principais habilidades de desempenho necessárias para a sua realização. Descrevem-se também os materiais necessários e extras disponíveis para a realização das mesmas.

Assim procedendo, foram elaborados 17 itens, sendo dez da Seção 1, que se refere à habilidade motora, e sete da Seção 2, relativa à habilidade de processo. A versão preliminar foi elaborada com esses itens. Para melhor ilustrar o instrumento, a seguir apresenta-se um item da Seção 1 de habilidades motoras.

Quadro 1 - Exemplificação de um item do instrumento da Seção 1 de habilidades motoras.

\begin{tabular}{|c|c|}
\hline \multicolumn{2}{|c|}{$\begin{array}{l}\text { A criança é capaz de usar as duas mãos de modo eficiente em atividades bimanuais (exemplo: segurar a cola com } \\
\text { uma mão e rosquear a tampa com a outra)? }\end{array}$} \\
\hline COLUNA 1 & COLUNA 2 \\
\hline ( ) capaz sem dificuldade & usar as duas mão \\
\hline ( ) capaz com pouca dificuldade & ( ) precisa de pouca ajuda para usar as duas $\mathrm{m}$ \\
\hline ( ) capaz com muita dificuldade & ( ) precisa de muita ajuda para usar as duas mãos em atividades bimanuais \\
\hline ( ) incapaz & ( ) a terapeuta executa este passo da tarefa sem a participação da criança \\
\hline
\end{tabular}

Fonte: Zafani (2013, p. 55)

Essa versão foi submetida à análise de três juízes, cujos resultados são apresentados a seguir.

\subsection{ANÁlise dos DADOS DO QUESTIONÁRIO DOS JUÍZES E ADEQUAÇÓES REALIZADAS NO INSTRUMENTO}

A partir dos resultados obtidos com o questionário aplicado junto aos juízes, foi considerada pertinente a realização de algumas adequaçôes no instrumento.

O primeiro exemplo se refere à definição das alternativas da Coluna 1, relativa à capacidade e incapacidade, e o segundo exemplo, à definição das alternativas da Coluna 2, correspondente à independência e dependência.

Os significados atribuídos a cada uma das alternativas de respostas foram revisados, sendo esta uma das sugestóes dadas por dois juízes. No Quadro 2, apresentam-se na coluna à 
esquerda os significados atribuídos previamente e na coluna à direita apresentam-se as alteraçóes realizadas.

Quadro 2 - Revisão e modificação dos significados atribuídos às alternativas de respostas.

\begin{tabular}{|c|c|}
\hline amente & Revisáo e modificaçáo dos significados adotados \\
\hline $\begin{array}{l}\text { A criança deverá ser considerada capaz sem dificul- } \\
\text { dade, capaz com pouca dificuldade e capaz com muita } \\
\text { dificuldade quando tiver aptidáo para executar uma } \\
\text { tarefa. } \\
\text { A criança deverá ser considerada incapaz quando } \\
\text { tiver limitaçôes que impedem a realização da tarefa. }\end{array}$ & $\begin{array}{l}\text { A criança deverá ser considerada: } \\
\text { Capaz sem dificuldade: quando a criança não apresentar } \\
\text { dificuldade para realizar a tarefa, tendo um desempenho } \\
\text { eficiente. } \\
\text { Capaz com pouca dificuldade: quando a criança apresentar } \\
\text { pouca dificuldade para realizar a tarefa, que interfere, mas } \\
\text { não impede a sua realização. } \\
\text { Capaz com muita dificuldade: quando a criança apresentar } \\
\text { muita dificuldade para realizar a tarefa, que interfere, mas } \\
\text { não impede a sua realizaçấo. } \\
\text { Incapaz: quando a criança apresentar uma dificuldade que } \\
\text { impede a realizaçáo da tarefa. }\end{array}$ \\
\hline $\begin{array}{l}\text { como independente quando a criança realizar a } \\
\text { tarefa sem precisar de nenhum tipo de auxílio; esta } \\
\text { possibilidade equivale a primeira alternativa de } \\
\text { resposta da Coluna } 2 \text {, não precisa de ajuda. } \\
\text { O desempenho da criança deverá ser considerado } \\
\text { como dependente quando a criança precisar de au- } \\
\text { xílio verbal, motor ou de algum dispositivo (poden- } \\
\text { do este ser uma bengala, andador, mobília, entre } \\
\text { outros) para conseguir realizar determinado passo } \\
\text { da tarefa; esta possibilidade equivale a segunda ou a } \\
\text { terceira alternativa de resposta da Coluna 2, precisa } \\
\text { de pouca ajuda ou precisa de muita ajuda. } \\
\text { O desempenho deverá ser considerado dependente } \\
\text { também, quando a terapeuta executar o passo da } \\
\text { tarefa sem a participação da criança; esta possibili- } \\
\text { dade equivale a quarta alternativa de resposta da } \\
\text { Coluna } 2 \text {. }\end{array}$ & $\begin{array}{l}\text { A criança: } \\
\text { Não precisa de ajuda: quando realizar a tarefa sem precisar } \\
\text { de auxílio motor ou verbal da terapeuta, podendo fazer } \\
\text { uso de recursos (andador, cadeira de rodas, material escolar } \\
\text { adaptado, entre outros) para tanto. } \\
\text { Precisa de pouca ajuda: quando precisar de pouco auxílio } \\
\text { motor ou verbal da terapeuta para realizar a tarefa, reque- } \\
\text { rendo esse auxílio mesmo com o uso do recurso. } \\
\text { Precisa de muita ajuda: quando precisar de muito auxílio } \\
\text { motor ou verbal da terapeuta para realizar a tarefa, reque- } \\
\text { rendo esse auxílio mesmo com o uso do recurso. } \\
\text { A terapeuta executa o passo da tarefa sem a participação da } \\
\text { criança: quando a terapeuta executar o passo da tarefa sem } \\
\text { a participaçáo da criança. }\end{array}$ \\
\hline
\end{tabular}

Fonte: Zafani (2013, p. 58)

Foi realizada também a modificação de alguns complementos das alternativas de respostas da Coluna 2, conforme destacado em itálico no exemplo a seguir: antes da modificação= não precisa de ajuda para puxar o zíper; e depois da modificação= não precisa de ajuda para puxar o ziper do estojo. Tais alteraçóes foram realizadas a fim de favorecer o entendimento dos pais e dos professores, indo ao encontro das sugestôes dos juízes.

Um dos juízes apontou que alguns itens do Protocolo de Observação não possuem uma linguagem acessível e de fácil compreensão, pois considerou que os enunciados de alguns deles estavam confusos e isto talvez dificultasse o entendimento por parte dos pais. Esse mesmo juiz sugeriu também que os exemplos contidos nos enunciados dos itens de habilidades de processo fossem melhorados. 
Foi realizada uma revisão criteriosa de todos os itens do Protocolo de Observação da Seção 1 e da Seção 2. Realizou-se também, uma revisão na questão de número 4 do Roteiro de Análise de Atividade de Pintura e Colagem referente às etapas sequencias das atividades. Esta revisão permitiu notar aspectos do desempenho importantes de serem avaliados, que não constavam no instrumento, e permitiu enriquecer a análise realizada.

Por meio desses procedimentos considerou-se relevante acrescentar e modificar o enunciado de alguns itens do instrumento, tanto na Seção 1 quanto na Seção 2.

Após estas revisões, o instrumento passou a ter 20 itens. A Seção 1 passou a ter 13 itens (foram acrescentados três itens), ao invés de 10. A Seção 2 permaneceu com sete itens, pois três itens foram excluídos por terem sido considerados subjetivos, e três novos itens foram acrescentados nesta seção.

Estas adequações no instrumento resultaram em sua versão final, intitulada "Protocolo de Observação do Desempenho de Crianças com Deficiência Física na Realização de Atividades de Pintura e Colagem"'1.

Foi elaborado com base na versão final do instrumento um Roteiro com exemplos de ajudas motoras e verbais que podem ser oferecidas para a criança durante a execução das atividades de pintura e colagem em cada um dos itens, a fim de possibilitar maior entendimento acerca das ajudas a serem oferecidas a criança e viabilizar o uso do instrumento por pessoas que não possuem familiarização com essa ferramenta.

\subsection{Procedimentos para a produçấo do material, aplicação do Protocolo de OBSERVAÇÃo E ANÁLISE de DAdOS}

No processo de construção do instrumento, além de ter sido desenvolvida uma série de atividades até alcançarmos a versão final, foi necessário sistematizar os procedimentos para a produção do material, aplicação do Protocolo de Observação e análise de dados.

\subsubsection{ProduÇáo do Material}

$\mathrm{Na}$ sala em que é realizada a filmagem deve, haver duas cadeiras, uma para a criança e outra para o avaliador, e duas mesas, sendo uma para fazer a atividade e a outra para a colocação dos materiais disponibilizados para a sua execução. Entre as duas mesas, é necessária uma distância de aproximadamente um metro e meio, a fim de possibilitar a observação do deslocamento da criança no ambiente, sendo este um dos aspectos a ser analisado pelos pais e professores. Essas informaçôes quanto aos materiais e à organização da sala estão descritas de maneira detalhada na Descrição dos materiais e da organização da sala para a realização das atividades de pintura e colagem.

Antes de ser proposta a realização da atividade de pintura e colagem, conta-se uma história à criança a fim de contextualizar a atividade que será realizada. Em seguida, são fornecidas as instruçóes necessárias para que a criança execute a atividade tendo como base o Roteiro de

\footnotetext{
${ }^{11}$ Ressalta-se que outros estudos estão em andamento objetivando identificar se a descrição dos procedimentos, constantes na dissertaçâo apresenta-se de forma clara permitindo o uso do protocolo sem a necessidade de treinamento específico ao usuário.
} 
instruçóes que devem ser fornecidas as crianças de quatro a nove anos. Posteriormente, o avaliador da início à atividade e a criança deve organizar suas açóes tendo em vista as instruçóes recebidas.

Para o registro do desempenho da criança utiliza-se uma filmadora, posicionada sobre um tripé. A filmagem é realizada individualmente, registram-se todas as fases do desenvolvimento da atividade, desde a contação de história, seguida das instruçóes fornecidas pelo avaliador antes de a criança iniciar a atividade e a realização da atividade propriamente dita, até o momento de sua finalização, incluindo-se os deslocamentos da criança no ambiente.

Concluída a filmagem, o avaliador, por meio de sua visualização, verifica se os registros focais permitem a pontuação de todos os itens do Protocolo de Observação. Caso seja identificado a presença de itens difíceis e/ou impossíveis de serem pontuados devido à inadequação da visualização das tomadas focais, uma nova filmagem deve ser realizada.

Se a filmagem estiver adequada, será editada pelo avaliador. Ressalta-se que, normalmente, a criança não executa a atividade exatamente na mesma ordem em que os itens de avalição aparecem no Protocolo. Diante disso, na edição são adicionadas legendas a fim de direcionar o olhar dos pais e professores para os itens do Protocolo de Observação que são pontuados por eles. Essas legendas contemplam o número do item do Protocolo de Observação correspondente a habilidade motora ou de processo observada, e uma descrição sucinta do que este item avalia.

\subsubsection{Aplicaçáo do Protocolo de Observaçáo}

O avaliador se reúne em dias separados com os pais e professores para assistir a filmagem e preencher o Protocolo de Observação.

Primeiramente, o avaliador deve esclarecer aos pais e professores que, conforme forem assistindo a filmagem da criança executando a atividade de pintura e colagem, devem preencher o Protocolo de Observação. Para os participantes preencherem os itens do Protocolo de Observação, o avaliador deve pausar a filmagem e voltar cenas da filmagem quando solicitado.

Os participantes recebem o esclarecimento de que o instrumento é dividido em duas partes, uma parte em que irão observar a eficiência da criança ao movimentar os objetos e a si própria no ambiente (Seção 1) e outra em que irão observar a qualidade do desempenho da criança nas áreas de atenção, compreensão, noção espacial e percepção visual (Seção 2).

Deve ser enfatizado que, na Seção 1 de habilidades motoras, são avaliadas apenas as ajudas motoras fornecidas pelo avaliador; as ajudas verbais não devem ser pontuadas. Já na Seção 2 de habilidades de processo, as ajudas motoras fornecidas pelo avaliador não devem ser consideradas; apenas as ajudas verbais serão avaliadas.

Na sequência, o enunciado de cada um dos itens é lido e explicado pelo avaliador, com ênfase ao que deve ser observado neles a fim de direcionar o olhar dos participantes para os aspectos de desempenho que serão observados na filmagem. Foi elaborado um Roteiro de instruçóes que devem ser passadas aos pais e professores em cada item. 
As alternativas de resposta da Coluna 1 e Coluna 2, bem como o significado de cada uma delas também são apresentadas aos pais e professores. Estes são instruídos a assinalar uma alternativa de resposta da Coluna 1 e uma da Coluna 2 em cada um dos itens.

Finalizadas as instruções, o avaliador sana eventuais dúvidas dos pais e professores em relação ao Protocolo de Observação e à execução da tarefa. Verificado que os participantes não têm dúvidas, a apresentação da filmagem e o preenchimento do instrumento devem ser iniciados.

\subsubsection{Análise dos dados do Protocolo de Observaçáo}

O Protocolo de observação contém 20 itens, distribuídos em duas seçôes. A Seção 1 contém 13 itens que avaliam as habilidades motoras da criança na execução da atividade; a Seção 2 contém 7 itens que avaliam as habilidades de processo da criança na execução da atividade. Em cada item do Protocolo de Observação, há duas colunas, Coluna 1 e Coluna 2, contendo alternativas de respostas.

A Coluna 1 do Protocolo de Observação é constituída por quatro alternativas de respostas referentes à capacidade ou incapacidade da criança na execução da atividade: incapaz, capaz com muita dificuldade, capaz com pouca dificuldade e capaz sem dificuldade. Devem ser atribuídos os seguintes valores a cada alternativa de resposta: 0 à alternativa de resposta incapaz, 1 à alternativa de resposta capaz com muita dificuldade, 2 à alternativa de resposta capaz com pouca dificuldade e 3 à alternativa de resposta capaz sem dificuldade.

A Coluna 2 do Protocolo de Observação é constituída por quatro alternativas de respostas referentes à independência ou dependência da criança na execução da atividade: $a$ terapeuta executa este passo da tarefa sem a participação da criança, precisa de muita ajuda, precisa de pouca ajuda e não precisa de ajuda. Devem ser atribuídos os seguintes valores a cada alternativa de resposta: 0 à alternativa de resposta a terapeuta executa esse passo da tarefa sem a participaçáo da criança, 1 à alternativa de resposta precisa de muita ajuda, 2 à alternativa de resposta precisa de pouca ajuda e 3 à alternativa de resposta não precisa de ajuda.

$\mathrm{Na}$ Seção 1 de habilidades motoras (HM), podem ser calculados dois escores, um que expressa o aspecto da capacidade/incapacidade $(\mathrm{C} / \mathrm{I})$, e outro relativo à independência/dependência (I/D). Como a Seção 1 de HM contém 13 itens, cada um destes escores (HM (C/I) e $H M(I / D))$ pode variar de zero a 39. Além disso, pode ser calculado o escore total obtido na seção de HM $(H M(T))$, através da soma dos escores relativos à $\mathrm{C} / \mathrm{I}$ com o de $\mathrm{I} / \mathrm{D}$, podendo variar de 0 a 78 .

Na Seção 2 de habilidades de processo (HP) também podem ser calculados dois escores, um que expressa o aspecto da capacidade/incapacidade $(\mathrm{C} / \mathrm{I})$, e outro relativo à independência/dependência (I/D). Como a Seção 2 de HP contém sete itens, cada um destes escores (HP (C/I) e HP (I/D)) pode variar de zero a 21. Pode ser calculado também, o escore total obtido na seção de $\mathrm{HP}(H P(T))$, através da soma dos escores relativos à C/I com o de I/D, podendo variar de zero a 42 .

Pode ser calculado o escore total referente à $\mathrm{C} / \mathrm{I}(\mathrm{C} / I(T))$, através da soma do escore de C/I obtido na seção de HM com o de C/I obtido na seção de HP. O escore C/I (T) pode variar de zero a 60 . Bem como, o escore total referente à I/D (I/D (T)), através da soma do es- 
core I/D obtido na seção de HM com o de I/D obtido na seção de HP. O escore I/D (T) pode variar de zero a 60 .

Por fim, para a análise global, pode ser calculado o escore total (ET) por meio da soma do escore HM (T) com o de HP (T), podendo variar de 0 a 120.

É possível calcular nove escores de avaliação do pai e nove do professor para cada criança. Através dos escores obtidos é possivel realizar diferentes análises, entre elas: comparar a avaliação do pai com a do professor, comparar intra pai e intra professor as avaliaçóes de diferentes aspectos do desempenho, comparar antes e depois de alguma intervenção, comparar avaliaçóes feitas em diferentes momentos para verificar evolução, usar a avaliaçáo como parte do procedimento de capacitação de pais/professores para aguçar sua observação, etc.

\section{Conclusóes}

As aplicações iniciais do Protocolo de Observação têm demonstrado que todos os procedimentos necessários para o seu uso são adequados e fornecido evidências da sua adequação quanto à linguagem e formato para a população que fará uso dele (pais e professores). Além disso, têm revelado que o Protocolo de Observação está cumprindo o seu objetivo principal, que é o de mensurar a percepção dos pais e dos professores em relação ao desempenho de crianças com deficiência física em uma atividade habitualmente realizada no contexto escolar.

Destaca-se a necessidade de se realizarem investigaçóes que levem em consideração a maneira como segmentos sociais importantes na construção da Educação Inclusiva, entre eles pais e professores, percebem a criança com deficiência física. $\mathrm{O}$ percepto formado a respeito da criança determina e orienta o tipo de relação estabelecida entre eles (pais-filhos e professor-aluno), a qual pode exercer influência sobre a competência que a criança irá apresentar no seu dia a dia e no contexto escolar.

A percepção do pai e a do professor devem também ser usadas como um indicador da qualidade e natureza da relação que mantém com a criança. Isto precisa ser levado em conta na orientação a pais e professores, na avaliação da criança e na decisão do que fazer com a criança com a colaboração de pais e professores.

\section{REFERÊNCIAS}

COSTER, W. J. et al. School Function Assesment: user manual. San Antonio: Therapy Skill Builders, 1998.

CREPEAU, E. B. Análise de Atividades: uma forma de refletir sobre o desempenho ocupacional. In: NEISTADT, M. E.; CREPAU, E. B. (Org.). Willard \& Spackman: terapia ocupacional. 9.ed. Rio de Janeiro: Guanabara Koogan, 2002. p.121-133.

FARIA, M. G. A. Adaptação da avaliação de habilidades motoras e de processo-Versão escolarpara crianças brasileiras de 4 a 8 anos de idade. 2004. Dissertação (Mestrado em Ciência da Reabilitação) - Universidade Estadual de Minas Gerais, Belo Horizonte, 2004.

FERRAZ, M. B. et al. Crosscultural reliability of the physical ability dimension of the Health Assessment Questionnaire. Journal of Rheumatology, Toronto, v.17, n.6, p.813-817, 1990. 
FERREIRA, S. H. A.; BARRERA, S. D. Ambiente familiar e aprendizagem escolar em alunos da educação infantil. Psico, Porto Alegre, v.41, n.4, p.462-472, 2010.

FERREIRA, I. L.; CALDAS, S. P. S. Atividades na pré-escola. São Paulo: Saraiva, 2002.

GESELL, A. A criança dos 5 aos 10 anos. São Paulo: Martins Fontes, 1993. A criança do 0 aos 5 anos. São Paulo: Martins Fontes, 2003.

HASTORF, A. H.; SCHNEIDER, D. J.; POLEFKA, J. Percep̧̧ão de pessoa. São Paulo: Blucher: EDUSP, 1973.

MANCINI, M. C. Inventário de avaliação pediátrica de incapacidade (PEDI): manual da versão brasileira adaptada. Belo Horizonte: UFMG, 2005.

OLIVEIRA, A. K. C. Repertório funcional de crianças com paralisia cerebral: a perspectiva de cuidadores e profissionais. 2012. 135f. Dissertação (Mestrado em Terapia Ocupacional) Universidade Federal de São Carlos, São Carlos, 2012.

OMOTE, S. et al. Mudança de atitudes sociais em relação à inclusão. Paidéia, Ribeirão Preto, v.15, n.32, p.387-398, 2005.

RODRIGUES, A.; ASSMAR, E. M. L.; JABLONSKI, B. Psicologia social. Petrópolis: Vozes, 2005.

SILVA, C. C. B.; EMMEL, M. L. G. Jogos e brincadeiras: roteiro de análise de atividades para o terapeuta ocupacional. Cadernos de Terapia Ocupacional da UFSCar, Sáo Carlos, v.4, n.1-2, p.46-62, 1993.

SILVA, A. M.; MENDES, E. G. Família de crianças com deficiência e profissionais: componentes da parceria colaborativa na escola. Revista Brasileira de Educação Especial, Marília, v.14, n.2, p.217-234, 2008.

SPODEK, B.; SARACHO, O. N. Ensinando crianças de três a oito anos. Porto Alegre: Artmed, 1998.

UDSMR. UNIFORM DATA SYSTEM FOR MEDICAL REHABILITATION. Guide for the uniform data set for medical rehabilitation (adult FIM), Version 4.0. Buffalo, New York: UB Foundation Activities, 1993.

ZAFANI, M. D. Percepção de pais e professores acerca do desempenho de crianças com deficiência fisica em atividades do contexto escolar. 2013. 221f. Dissertação (Mestrado em Educação) Faculdade de Filosofia e Ciências, Universidade Estadual Paulista, Marília, 2013.

Recebido em: 22/04/2014

Reformulado em: 01/03/2015

Aprovado em: 03/03/2015 